\title{
Effect of Different Polishing Systems on the Surface Roughness and Gloss of Novel Nanohybrid Resin Composites
}

\author{
Hanan A. N. Soliman ${ }^{1}$ Naglaa Rizk Elkholany ${ }^{2}$ Hamdi H. Hamama ${ }^{2, \bullet ~ F a t m a ~ M . ~ E L-S h a r k a w y ~}{ }^{3}$ \\ Salah H. Mahmoud ${ }^{2}$ John C. Comisi ${ }^{4} \odot$
}

${ }^{1}$ Department of Operative Dentistry, Faculty of Dentistry,

Address for correspondence John C. Comisi, DDS, MAGD,

Kafrelsheikh University, Kafrelsheikh, Egypt

${ }^{2}$ Department of Operative Dentistry, Faculty of Dentistry, Department of Oral Rehabilitation, Restorative Dentistry, Medical University of South Carolina, 173 Ashley Avenue, BSB 548, MSC 507 Mansoura University, Mansoura, Egypt

${ }^{3}$ Department of Photometry, National Institute of Standards, Giza, Charleston, SC 29425, United States (e-mail: comisi@musc.edu).

Egypt

${ }^{4}$ Department of Oral Rehabilitation, Restorative Dentistry, Medical University of South Carolina, Charleston, South Carolina, United States

Eur J Dent 2021;15:259-265

\begin{abstract}
Keywords

- microhybrid

- nanohybrid

- roughness

- gloss

- polish

- resin composite

restorative material

Objectives To evaluate the surface roughness and gloss of three nanohybrid resin composites after polishing with three different polishing systems.

Materials and Methods A total number of 112 disc specimens $(10 \times 3 \mathrm{~mm})$ were prepared from nanohybrid-Empress Direct (ID), Grandio (GR), Filtek Z350 (Z350) and a microhybrid resin composite restorative materials-Filtek Z250 (Z250). Following 24 -hour storage in $37^{\circ} \mathrm{C}$ distilled water, each composite group $(n=28)$ was assigned into four groups $(n=7)$ according to finishing/polishing $(F / P)$ system: Mylar strip, Optrapol, Politip, and Sof-Lex (SL). The surface roughness (Ra, mm) was measured by a novel three-dimensional method using an image analysis software attached to an environmental scanning electron microscope. A glossometer was used to measure the surface gloss.

Results Statistical analysis used was ANOVA test. Two-way Anova test revealed that the "type of composite" and "F/P techniques" had a significant effect on both surface roughness and gloss of the tested resin composite materials $(p<0.05)$. Tukey's post hoc test showed that ID, GR, and Z350 revealed lower surface roughness and higher surface gloss than Z250 within the same polishing system $(p<0.05)$. Sof-Lex polishing discs produced the lowest surface roughness and highest surface gloss values compared with Optrapol and Politip $(p<0.05)$.

Conclusion The tested $F / P$ systems provided comparable surface roughness and gloss for nanohybrid composites. The Sof-Lex system provided the best surface roughness and gloss for nanohybrid composites.
\end{abstract}

\section{Introduction}

The durability of restorations is one of the main concerns in restorative dentistry. Due to the growing patient's esthetic

published online October 27, 2020
DOI https://doi.org/

$10.1055 / \mathrm{s}-0040-1718477$ ISSN 1305-7456. demand, resin composite restorations become the first material of choice in restoring teeth. It has been reported that the surface topography of the restoration significantly affects the clinical success of resin composite restorations. ${ }^{1,2}$ Hence,

(C) 2020. European Journal of Dentistry.

This is an open access article published by Thieme under the terms of the Creative Commons Attribution-NonDerivative-NonCommercial-License, permitting copying and reproduction so long as the original work is given appropriate credit. Contents may not be used for commercial purposes, or adapted, remixed, transformed or built upon. (https://creativecommons.org/licenses/by-nc-nd/4.0/)

Thieme Medical and Scientific Publishers Pvt. Ltd., A-12, 2nd Floor, Sector 2, Noida-201301 UP, India 
for creating successful dental composite restorations, it is mandatory to obtain adequate surface smoothness and gloss.

A rougher surface texture can lead to increased plaque retention, gingival inflammation, irritation of the tongue, lips, and cheeks, and decreased gloss and increased discoloration of the material surface which can affect the restorations' esthetics. $^{3-5}$ Smooth surfaces reduce plaque accumulation, recurrent caries, bacterial adhesion, and the discoloration of restored teeth over the long term. ${ }^{6}$

Gloss also plays an important role in the esthetic appearance of composite restorations and their blending to surrounding teeth. ${ }^{7}$ High gloss reduces the effect of a color difference between resin composite and surrounding enamel. The color of reflected light is predominant rather than the color of the underlying composite. ${ }^{8}$ When different techniques are proposed, not only their efficiency in maintaining a smooth surface but also their ability to obtain a gloss surface have to be considered. Proper contour, smoothness, and high gloss can produce the desired appearance of natural tooth structure desired by patients. ${ }^{9}$ Therefore, it is of paramount importance to obtain smooth and glossy surfaces.

The final surface polish of resin composite restorations could be affected by many variables, such as resin composite type, resin monomer type, the load of filler particles, as well as finishing/polishing (F/P) system used. ${ }^{10,11}$

When different techniques are proposed, not only their efficiency in maintaining a smooth surface but also their ability to obtain a gloss surface have to be considered. ${ }^{12}$ This study aims to evaluate the effect of three F/P systems on the surface roughness and gloss of three nanohybrid resin composites and one microhybrid resin composite.

\section{Materials and Methods}

Three nanohybrid resin composites and one microhybrid resin composite were used in the current study (-Table $\mathbf{1}$ ).

\section{Surface Roughness Measurements}

\section{Specimen Preparation and Study Design}

A total of 112 specimens (28 specimens per each restorative material) were fabricated using a cylindrical Teflon mold (10 mm wide $\times 2 \mathrm{~mm}$ tall) and covered by Mylar strip (SS White, United States). Restorative materials were applied and light cured following the manufacturers' instructions with an LED light-curing unit (Bluephase C8, Ivoclar Vivadent, AG, Schaan, Liechtenstein) with light irradiance $800 \mathrm{~mW} / \mathrm{cm}^{2}$. The light irradiance was verified using a digital readout dental radiometer (Bluephase Meter, Ivoclar Vivadent). Each restorative material group was further divided into four subgroups according to the finishing and polishing system used; one control (Mylar strip) and three testing subgroups $(n=7)$.

Group 1: Specimen maintained without F/P after removal of Mylar strip to act as a control group (seven specimens per each material group).

The remaining 84 specimens were treated with superfine grit finishing diamond bur (25 $\mu \mathrm{m}$, no. 837 KREF.314.014, Brasseler) attached to a high-speed handpiece with a cooling system for 30 seconds at 200,000 rpm to simulate the clinical procedure of "primary" finishing of resin composite restorations. A slow-speed handpiece $(10,000 \mathrm{rpm})$ with standardized pressure ( $2 \mathrm{~kg}$ ) and brushing strokes for 30 seconds (10 seconds per grit) was used for all polishing according to the manufacturer's instructions. A conscious effort was made to standardize the strokes according to previous protocols. ${ }^{13,14}$

Group 2: The specimens were finished and polished with an Optrapol lens, a one-step system.

Group 3: The specimens were finished with Politip F and then polished with Politip P flames. After each polishing step, the specimen was rinsed with water spray and air dried to produce a smooth "uniform" surface.

Table 1 Materials used in the study

\begin{tabular}{|c|c|c|c|c|c|c|c|c|}
\hline $\begin{array}{l}\text { Restorative } \\
\text { material }\end{array}$ & Specification & Shade & Manufacture & Matrix & Filler & $\begin{array}{l}\text { Average } \\
\text { filler } \\
\text { size }(\mu \mathrm{m})\end{array}$ & $\begin{array}{r}\text { Fil } \\
\text { weigh }\end{array}$ & $\begin{array}{l}\text { er loading } \\
\text { t/volume (\%) }\end{array}$ \\
\hline $\begin{array}{l}\text { IPS Empress } \\
\text { Direct (ID) }\end{array}$ & $\begin{array}{l}\text { Nanohybrid } \\
\text { composite }\end{array}$ & $\begin{array}{l}\text { A3 } \\
\text { Dentin }\end{array}$ & $\begin{array}{l}\text { Ivoclar } \\
\text { Vivadent } \\
\text { AG, Schaan, } \\
\text { Liechtenstein }\end{array}$ & $\begin{array}{l}\text { Bis GMA, } \\
\text { UDMA } \\
\text { TEGMA. }\end{array}$ & $\begin{array}{l}\text { Barium glass, Ba-Al-fluorosilicate } \\
\text { glass, and mixed oxide }\end{array}$ & 0.7 & 81.2 & 64.3 \\
\hline Grandio (GR) & $\begin{array}{l}\text { Nanohybrid } \\
\text { composite }\end{array}$ & A3 & $\begin{array}{l}\text { Voco, } \\
\text { Cuxhaven, } \\
\text { Germany }\end{array}$ & $\begin{array}{l}\text { Bis-GMA, } \\
\text { UDMA, } \\
\text { TEGD } \\
\text { MA, DMA }\end{array}$ & $\begin{array}{l}\text { Glass-ceramic microfillers } \\
\text { Silicon dioxide nanofillers }\end{array}$ & $\begin{array}{l}1 \\
0.020-0.060\end{array}$ & 87 & 71.4 \\
\hline Filtek Z350 & $\begin{array}{l}\text { Nanohybrid } \\
\text { composite }\end{array}$ & A3 & $\begin{array}{l}\text { 3M ESPE, } \\
\text { St. Paul, } \\
\text { Minnesota, } \\
\text { United States }\end{array}$ & $\begin{array}{l}\text { Bis-GMA, } \\
\text { UDMA, Bis- } \\
\text { EMA, TEGM } \\
\text { A and } \\
\text { PEGDMA }\end{array}$ & $\begin{array}{l}\text { Surface modified zirconia/silica } \\
\text { Nonagglomerated/nonaggre- } \\
\text { gated surface-modified silica } \\
\text { particles }\end{array}$ & $\begin{array}{l}0.1-10 \\
0.02\end{array}$ & 81.8 & 67.8 \\
\hline Filtek Z250 & $\begin{array}{l}\text { Microhybrid } \\
\text { composite }\end{array}$ & A3 & $\begin{array}{l}\text { 3M ESPE, } \\
\text { St. Paul, } \\
\text { Minnesota, } \\
\text { United States }\end{array}$ & $\begin{array}{l}\text { Bis-GMA, } \\
\text { UDMA, } \\
\text { Bis-EMA, } \\
\text { TEGDMA }\end{array}$ & Zirconia, silica & $0.01-3.5$ & $75-85$ & 60 \\
\hline
\end{tabular}

Abbreviations: Bis-GMA, bisphenol-A glycidyl methacrylate; DMA, dimethacrylate; PEGDMA, polyethylene glycol dimethacrylate; TEGDMA, triethylene glycol dimethacrylate; UDMA, urethane dimethacrylate. 
Table 2 Finishing systems used in the study

\begin{tabular}{|c|c|c|c|c|c|}
\hline Brand names & Specification & Manufacture & Type & Composition & Batch number \\
\hline Optrapol & $\begin{array}{l}\text { One-step polishing } \\
\text { system }\end{array}$ & $\begin{array}{l}\text { Ivoclar Vivadent AG, } \\
\text { Schaan, Liechtenstein }\end{array}$ & Rubber lens & $\begin{array}{l}\text { Caoutchouc, silicone, } \\
\text { carbide, aluminum oxide, } \\
\text { titanium oxide, iron } \\
\text { oxide }\end{array}$ & SL1794 \\
\hline Politip & $\begin{array}{l}\text { Two-step polishing } \\
\text { system }\end{array}$ & Ivoclar Vivadent & Rubber flame & $\begin{array}{l}\text { Silicone rubber, silicon } \\
\text { carbide particles, and } \\
\text { titanium oxide }\end{array}$ & Pl1829 \\
\hline Sof-Lex & $\begin{array}{l}\text { Three-step polishing } \\
\text { system }\end{array}$ & $\begin{array}{l}3 \text { M Dental Products } \\
\text { ESPE, St. Paul, } \\
\text { Minnesota, United } \\
\text { States }\end{array}$ & Silicon disc & $\begin{array}{l}\text { Aluminum } \\
\text { oxide } \\
\text { Medium }(40 \mathrm{~mm}) \\
\text { Fine }(24 \mathrm{~mm}) \\
\text { Superfine }(8 \mathrm{~mm})\end{array}$ & N204788 \\
\hline
\end{tabular}

Group 4: The specimens were finished and polished with a three-step Sof-Lex aluminum oxide disc system (- Table 2 ). The discs have a small round eyelet that snaps onto the mandrel, which was then mounted on a low-speed handpiece. The specimens were finished/polished with Sof-Lex discs in a descending sequence of abrasiveness, dark blue Sof-Lex disc (medium), fine Sof-Lex (blue), and superfine Sof-Lex (light blue) with uniform light pressure and a planar motion from the bulk of the restoration toward the margins. After each polishing step, the specimen was rinsed with water spray and air dried to produce a smoother, more uniform finish. After completing polishing procedures, specimens were rinsed, cleaned in an ultrasonic cleaner for 3 minutes and air dried.

The surface roughness ( $\mathrm{Ra}, \mathrm{mm}$ ) was measured by a novel three-dimensional (3D) method using an image analysis software attached to an environmental scanning electron microscope (ESEM) (Quanta 200, FEI Co., Oregon, United States) to provide both qualitative and quantitative assessments of surface roughness. Specimens were photomicrographed at $\times 1,000$ magnification. Those images were then analyzed quantitatively using microscopy installed image analysis software (XT document). The used microscope employed a scanned electron beam and electromagnetic lenses to focus and direct the beam on the specimen surface in an identical way as a conventional SEM. A very small, focused electron spot was scanned over a small specimen area. The beam electrons interacted with the specimen surface layer and produced various signals (information) that were collected with appropriate detectors. The output of these detectors modulated, via appropriate electronics, the screen of a monitor to form an image that corresponded to the information, pixel by pixel, emanating from the specimen surface. ${ }^{2}$

The images were captured, and software data were recorded and represented in an excel spreadsheet. ${ }^{15}$

\section{Gloss Measurements}

The same study design, which previously mentioned in surface roughness test, was followed in surface gloss testing. Surface gloss was measured with a glossometer (PICOGLOSS 560MC, ERICHSEN GmbH \& Co. KG, Germany). The measuring principle of this device is based on a light beam that strikes the surface at an angle of 60 degrees. ${ }^{16}$ The glossmeter measures the intensity of the reflected light and compares it with a reference value. ${ }^{17}$ Measurements were presented in gloss units (GU).

\section{Statistical Analysis}

Statistical analysis was performed using an SPSS (version 17) software program (SPSS; Chicago, Illinois, United States). Initially, the normal distribution of errors and the homogeneity of variances were checked by Shapiro-Wilk's test and Levene's test. Based on these preliminary analyses, data of each test were separately analyzed using the two-way analysis of variance (ANOVA) and Tukey's honestly significant difference post hoc test. A Pearson's test was performed to investigate the correlation between the surface roughness and surface gloss data. All analyses were performed at a significance level of $\alpha=0.05$.

\section{Results}

\section{Surface Roughness Results}

\section{Qualitative Evaluation}

Representative 3D images of different F/P procedures were observed with ESEM after scanning the entire surfaces of specimens. Each roughness image revealed three peaks, which are $(X, Y, Z)$ as follows:

$X$-coordinate represents the length of each peak.

$Y$-coordinate represents the width of each peak.

$Z$-coordinate represents the height of each peak.

At the $Z$-axis, the peaks or surface elevations were marked, and the height of each peak was automatically computed. Mean surface roughness values (Ra) were calculated for each specimen. Ra describes the arithmetic mean of all values of the roughness profile (R) over the evaluated length.

For all resin composites (-Fig. 1), it was observed relatively uniform surface topography in the control group (Mylar strip). In contrast, irregular surfaces are produced after polishing procedures (one-step Optrapol, two-step Politip, and multistep Sof-Lex). The topographical analysis showed that the smoothest surfaces associated with Sof-Lex, while the highest surface irregularities were observed with Optrapol among finishing techniques.

Among finishing techniques, as illustrated in - Fig. 2, the topographical analysis showed that the smoothest surface 


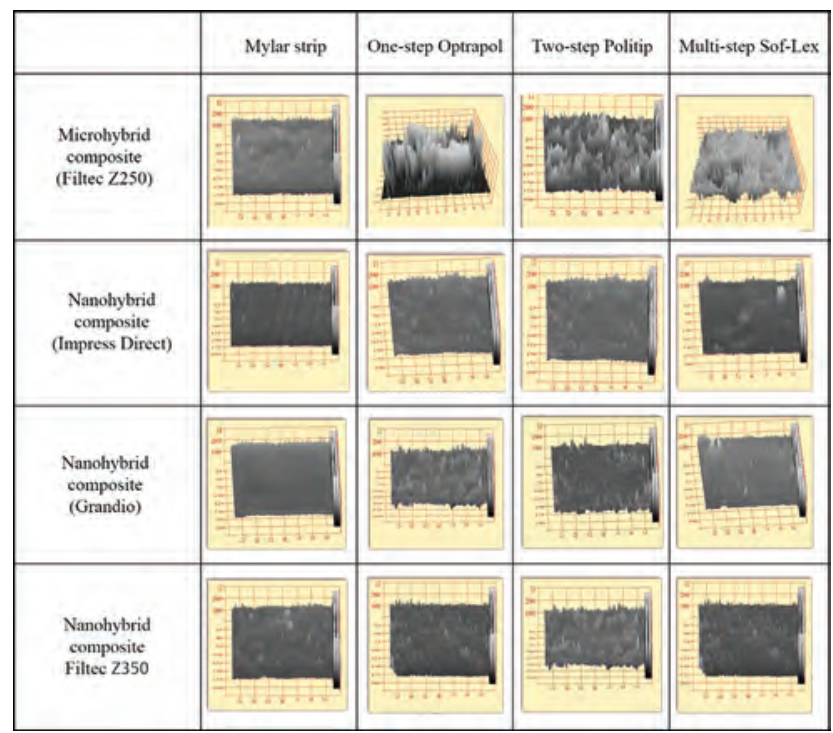

Fig. 1 Comparison between Filtek Z250, IPS Empress Direct, Grandio (GR), and Filtek Z350 in Mylar strip, one-step Optrapol, two-step Politip, and multistep Sof-Lex polishing systems.

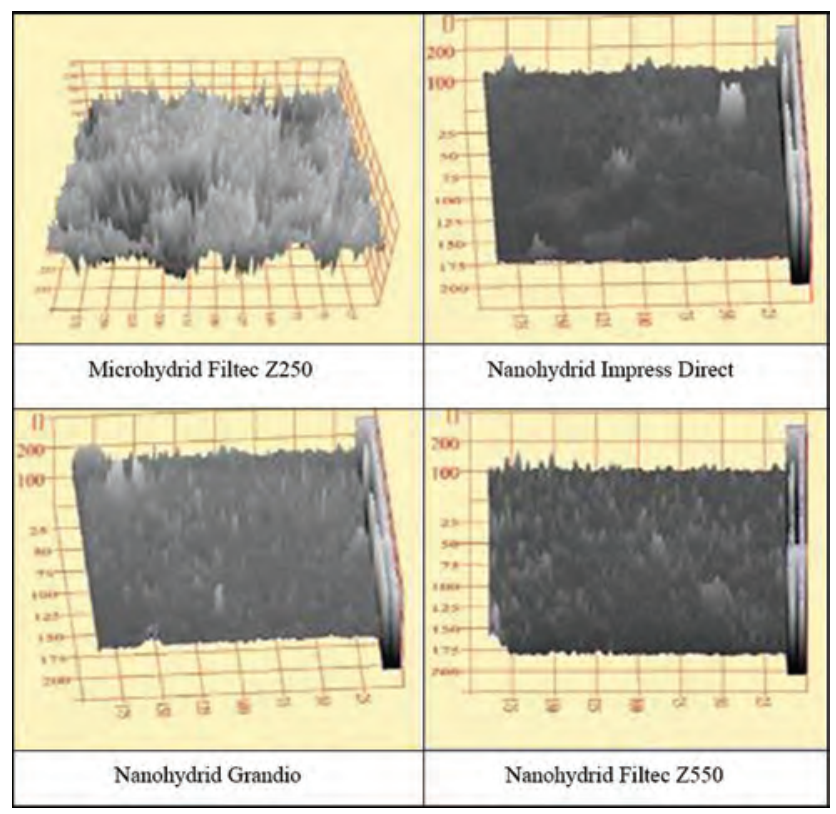

Fig. 2 Comparisons between composite materials after finishing/ polishing with Sof-Lex.

associated with Sof-Lex. For microhybrid composite (Z250) specimens, more irregularities were detected on the surface in comparison with nanohybrid (Impress Direct, Grandio, and Filtek Z350).

\section{Quantitative Evaluation}

A 3D surface roughness profile was automatically plotted. At the $Z$-axis, the peaks or surface elevations were marked and automatically computed. Mean surface roughness values (Ra) were calculated for each specimen. Ra describes the arithmetic mean of all values of the roughness profile $(R)$ over the evaluated length.
The results of a two-way ANOVA test revealed that "type of composite" and "F/P techniques" significantly affect the surface roughness values $(p>0.0001)$. The interaction of both variables was also significant ( $p>00.0001$ ). Mean Ra and standard deviation values of the four composite materials (IPS Empress Direct [ID], Grandio [GR], Filtek Z350 [Z350], and Filtek Z250 [Z250]) after different surface treatments are shown in - Table 3 .

\section{Surface Gloss Test}

The results of the two-way ANOVA test revealed that "type of composite" and " $\mathrm{F} / \mathrm{P}$ techniques" significantly affect the surface gloss values $(p=0.0001)$. Gloss values (GU) of the tested groups are shown in $\mathbf{- T a b l e ~} 4$.

\section{Discussion}

Successful restoration should replicate surface smoothness and gloss of human enamel. The present study compared the surface roughness and surface gloss of four different composite resin restorative materials: three nanohybrid (Empress Direct, Grandio, and Filtek Z350) and one microhybrid resin composites (Filtek Z250) before and after F/P with different systems. These restorative materials were selected based on filler size. Additionally, the polishing systems investigated in this study were selected according to the number of application steps to compare and evaluate the effectiveness of one-step polishers compared with two and multistep polishers.

Surface roughness can be measured by ESEM, which provides both qualitative and quantitative data of surface roughness. ${ }^{18}$ In the present study, surface roughness was measured by an ESEM, which can capture an image for the tested specimens with magnification up to $\times 100,000$. The main advantage of ESEM is that the specimens could be observed inside its low-vacuum chamber in a relatively wet condition. Moreover, it can examine the nonconducting, contaminated, hydrated, and even living samples without "long" tedious dehydration procedures, which may affect the integrity of the biological specimens. ${ }^{19}$ In comparison with SEM, ESEM provides a reliable idea about the material behavior in relatively humid environment. ${ }^{19}$

Nevertheless, the outcome of the roughness test of the current laboratory study revealed that the smoothest composite surfaces were obtained with Mylar strips; it is not applicable in a true clinical scenario. Mylar strips were used as a control group according to previous studies. ${ }^{20,21}$ Several previous studies supported that unpolished surfaces that obtained under Mylar strip of all tested composites were significantly smoother than polished specimens. ${ }^{22-24}$ However, the removal of the outermost composite layer by F/P procedures is necessary to produce a wear-resistant, harder, and color stabilized restoration. 25

The current study shows that the multiple-step system (Sof-Lex) is the most effective polishing method in the creation of a smooth surface for tested composites compared with the one- and two-step system. The superiority of this 
Table 3 Roughness values $(\mu \mathrm{m})$ of the tested groups

\begin{tabular}{|c|c|c|c|c|}
\hline Polishing systems & $\mathrm{Z} 250$ & ID & GR & $\mathrm{Z350}$ \\
\hline \multicolumn{5}{|l|}{ Group 1} \\
\hline Mylar strip & $0.299 \pm 0.03^{\mathrm{d}, \mathrm{A}}$ & $0.216 \pm 0.05^{\mathrm{c}, \mathrm{B}}$ & $0.214 \pm 0.05^{\mathrm{d}, \mathrm{B}}$ & $0.246 \pm 0.06^{\mathrm{d}, \mathrm{B}}$ \\
\hline \multicolumn{5}{|l|}{ Group 2} \\
\hline $\begin{array}{l}\text { One-step Optrapol } \\
\text { system }\end{array}$ & $1.606 \pm 0.03^{\mathrm{a}, \mathrm{A}}$ & $0.84 \pm 0.05^{\mathrm{a}, \mathrm{D}}$ & $0.953 \pm 0.09^{\mathrm{a}, \mathrm{C}}$ & $1.203 \pm 0.04^{\mathrm{a}, \mathrm{B}}$ \\
\hline \multicolumn{5}{|l|}{ Group 3} \\
\hline $\begin{array}{l}\text { Two-step Politip } \\
\text { system }\end{array}$ & $1.53 \pm 0.03 \mathrm{~b}, \mathrm{~A}$ & $0.72 \pm 0.06^{\mathrm{b}, \mathrm{D}}$ & $0.85 \pm 0.04^{b, c}$ & $0.917 \pm 0.04^{\mathrm{b}, \mathrm{B}}$ \\
\hline \multicolumn{5}{|l|}{ Group 4} \\
\hline $\begin{array}{l}\text { Multistep Sof-Lex } \\
\text { system }\end{array}$ & $1.323 \pm 0.03^{\mathrm{c}, \mathrm{A}}$ & $0.67 \pm 0.03^{\mathrm{b}, \mathrm{D}}$ & $0.72 \pm 0.05^{c, C}$ & $0.819 \pm 0.05^{c, B}$ \\
\hline
\end{tabular}

Note: Values are means \pm standard deviation. Groups identified by different superscripts were significantly different $(p<0.05)$. The same superscript letters (A-D) in the same row indicate no significant difference (Tukey's honestly significant difference [HSD] test; $p<0.05$ ). The same superscript letters (a-d) in the same column indicate no significant difference (Tukey's HSD test; $p<0.05$ ).

Table 4 Two-way analysis of variance of surface gloss values factor

\begin{tabular}{|c|c|c|c|c|}
\hline Polishing systems & $\mathrm{Z} 250$ & ID & GR & Z350 \\
\hline \multicolumn{5}{|l|}{ Group 1} \\
\hline Mylar strip & $51.57 \pm 4.2^{\mathrm{a}, \mathrm{B}}$ & $75.93 \pm 5.2^{\mathrm{a}, \mathrm{A}}$ & $76.57 \pm 4.7^{\mathrm{a}, \mathrm{A}}$ & $73.93 \pm 4.97^{\mathrm{a}, \mathrm{A}}$ \\
\hline \multicolumn{5}{|l|}{ Group 2} \\
\hline One-step Optrapol system & $32.14 \pm 1.8^{\mathrm{d}, \mathrm{B}}$ & $42.9 \pm 1.1^{\mathrm{d}, \mathrm{A}}$ & $42 \pm 2.02^{\mathrm{d}, \mathrm{A}}$ & $42 \pm 1.19^{c, A}$ \\
\hline \multicolumn{5}{|l|}{ Group 3} \\
\hline Two-step Politip system & $36.9 \pm 1.49^{c, B}$ & $46.79 \pm 2.6^{\mathrm{C}, \mathrm{A}}$ & $46.79 \pm 3.3^{\mathrm{C}, \mathrm{A}}$ & $45.7 \pm 3.98^{\mathrm{c}, \mathrm{A}}$ \\
\hline \multicolumn{5}{|l|}{ Group 4} \\
\hline Multistep Sof-Lex system & $41.9 \pm 1.5^{\mathrm{d}, \mathrm{B}}$ & $55.6 \pm 3.3^{\mathrm{b}, \mathrm{A}}$ & $55.86 \pm 2.6^{\mathrm{b}, \mathrm{A}}$ & $53.7 \pm 3.67^{\mathrm{b}, \mathrm{A}}$ \\
\hline
\end{tabular}

Note: Values are means \pm standard deviation. Groups identified by different superscripts were significantly different $(p<0.05)$. The same superscript letters (A-D) in the same row indicate no significant difference (Tukey's honestly significant difference [HSD] test; $p<0.05$ ). The same superscript letters (a-d) in the same column indicate no significant difference (Tukey's HSD test; $p<0.05$ ).

method could be explained by the sequential order of using decreased abrasiveness, which enhances the final surface texture. This result is not achieved with one-step polishing systems. ${ }^{26}$ The results of the current study were in agreement with the study by Venturini et al, ${ }^{27}$ who reported that the effective finishing system (abrasive) must incorporate relatively harder abrasives than the resin composite's filler particles. Otherwise, the polishing agent would only remove the soft resin matrix and leave the filler particles protruding from the surface. ${ }^{17}$ Moreover, the aluminum oxide cutting particles of Sof-Lex disc (which is higher than silicon particles of Politip and Optrapol) are harder than most filler particles of the resin composite used. ${ }^{28}$ This property allows removing of both fillers and soft resin matrix during finishing procedures. Also, Sof-Lex discs can remove both fillers particles as well as the matrix. ${ }^{15}$

A recent study by Rodrigues-Junior et $\mathrm{al}^{29}$ confirmed that the multistep systems produced lower surface roughness and higher gloss than the one-step system. Surface gloss is another factor playing an essential role in the longevity of resin composite restorations. ${ }^{16}$

In the present study, the highest gloss values were obtained with Mylar strips followed by the three-step polishing system, then the two-step polishing system, while the least gloss values were recorded with the one-step polishing system. These findings were in agreement with Lopes et $\mathrm{al}^{30}$ who reported that finishing and polishing procedures require sequential use of instrumentation with gradually smaller grained abrasives to achieve the desired glossy surface ultimately. Conversely, the outcome of this study disagreed with Da Costa et al (2007), ${ }^{17}$ who reported that one-step systems have the highest gloss values.

The results of this study showed that the surface roughness values of unpolished specimens were not exceeding $0.3 \mu \mathrm{m}$. Studies reported that patients could not detect rough surface when the Ra is $0.5 \mu \mathrm{m} .{ }^{31}$ In contrast, a previous study reported that dental plaque may accumulate on resin composite surfaces when the $\mathrm{Ra}$ is below $0.5 \mu \mathrm{m} .{ }^{32}$ The mean roughness value of three nanohybrid resin composites (ID, GR, and Z350) produced values below the maximum limit $(0.7-1.44 \mu \mathrm{m})$ at which dental plaque cannot accumulate on composite specimens.

In the present study, nanohybrid composites (ID, GR, and Z350) exhibited lower surface roughness than Z250. This finding can be attributed to their nanotechnology manufacturing techniques. The outcome of this study was in total 
agreement with several previous studies. ${ }^{9,33}$ The study by Mitra et $\mathrm{a}^{34}$ attributed this difference to the high filler content, the reduction of filler size, and an even filler distribution within the resin matrix. In addition to the strong chemical integration of nanoparticles into the resin matrix, the filler particles become situated as close together as possible to protect the resin matrix from abrasives. Thus, nanocomposites wear by breaking off individual primary particles rather than by breaking off larger particles, as in hybrid composites. ${ }^{11,34}$ The outcome of this study was in total agreement of several previous studies which stated that the nanohybrid material can be referred to as a "nanofiller loaded resin composite."35-37

The current study showed that the highest gloss values were recorded with nanofilled resin composite specimens. This result was in accordance with Heintze et $a l,^{38}$ who stated that gloss was material dependent. In the present study, there was a significant inverse linear relationship between roughness and gloss, which is reported previously in several studies. ${ }^{39,40}$ This relationship was previously reported by Watanabe et al, ${ }^{15}$ who stated that when the surface roughness is increased, the degree of random reflection of light will increase, consequently resulting in decreased gloss. Conversely, Heintze et $\mathrm{al}^{38}$ disagreed with this relationship and reported that correlations between gloss and roughness were in general absent.

\section{Conclusion}

In light of the results of the current study, it can be concluded that:

- Both surface roughness and gloss were significantly influenced by the $\mathrm{F} / \mathrm{P}$ systems and the composite resin filler particle size.

- A multistep F/P system (Sof-Lex) exhibits the most efficient $\mathrm{F} / \mathrm{P}$ protocol of resin composite restorations.

- There was an inverse relationship between surface roughness and surface gloss.

\section{Recommendation}

Further studies are needed to invent a new F/P system that can obtain a surface topography similar to those which can be obtained by Mylar strips.

\section{Conflict of Interest}

None declared.

\section{References}

1 Hossam AE, Rafi AT, Ahmed AS, Sumanth PC. Surface topography of composite restorative materials following ultrasonic scaling and its Impact on bacterial plaque accumulation. An in-vitro SEM study. J Int Oral Health 2013;5(3):13-19

2 Hafez R, Ahmed D, Yousry M, El-Badrawy W, El-Mowafy O. Effect of in-office bleaching on color and surface roughness of composite restoratives. Eur J Dent 2010;4(2):118-127

3 Bansal K, Gupta S, Nikhil V, Jaiswal S, Jain A, Aggarwal N. Effect of different finishing and polishing systems on the surface roughness of resin composite and enamel: an in vitro profilometric and scanning electron microscopy study. Int J Appl Basic Med Res 2019;9(3):154-158

4 Madhyastha PS, Hegde S, Srikant N, Kotian R, Iyer SS. Effect of finishing/polishing techniques and time on surface roughness of esthetic restorative materials. Dent Res J (Isfahan) 2017;14(5):326-330

5 Sturz CR, Faber F-J, Scheer M, Rothamel D, Neugebauer J. Effects of various chair-side surface treatment methods on dental restorative materials with respect to contact angles and surface roughness. Dent Mater J 2015;34(6):796-813

6 Beltrami R, Ceci M, De Pani G, et al. Effect of different surface finishing/polishing procedures on color stability of esthetic restorative materials: a spectrophotometric evaluation. Eur J Dent 2018;12(1):49-56

7 Camino Navarro R. Abrasion Effects on Time-Lasting Ceramic Stains and Glazes: A Comparison of Color Stability and Gloss Retention. 2019. https://doi.org/10.17615/h4pr-eg13

8 Suh YR, Ahn JS, Ju SW, Kim KM. Influences of filler content and size on the color adjustment potential of nonlayered resin composites. Dent Mater J 2017;36(1):35-40

9 Cenci MS, Venturini D, Pereira-Cenci T, Piva E, Demarco FF. The effect of polishing techniques and time on the surface characteristics and sealing ability of resin composite restorations after one-year storage. Oper Dent 2008;33(2):169-176

10 Pratap B, Gupta RK, Bhardwaj B, Nag M. Resin based restorative dental materials: characteristics and future perspectives. Jpn Dent Sci Rev 2019;55(1):126-138

11 Yazici AR, Tuncer D, Antonson S, Onen A, Kilinc E. Effects of delayed finishing/polishing on surface roughness, hardness and gloss of tooth-coloured restorative materials. Eur J Dent 2010;4(1):50-56

12 da Costa J, Adams-Belusko A, Riley K, Ferracane JL. The effect of various dentifrices on surface roughness and gloss of resin composites. J Dent 2010;38(Suppl 2) :e123-e128

13 Koh R, Neiva G, Dennison J, Yaman P. Finishing systems on the final surface roughness of composites. J Contemp Dent Pract 2008;9(2):138-145

14 de Oliveira ALBM, Garcia PP, Santos PAd, Campos JÁDB. Surface roughness and hardness of a composite resin: influence of finishing and polishing and immersion methods. Mater Res 2010;13(3):409-415

15 Watanabe T, Miyazaki M, Takamizawa T, Kurokawa H, Rikuta A, Ando S. Influence of polishing duration on surface roughness of resin composites. J Oral Sci 2005;47(1):21-25

16 O'Brien WJ, Johnston WM, Fanian F, Lambert S. The surface roughness and gloss of composites. J Dent Res 1984;63(5):685-688

17 Da Costa J, Ferracane J, Paravina RD, Mazur RF, Roeder L. The effect of different polishing systems on surface roughness and gloss of various resin composites. J Esthet Restor Dent 2007;19(4):214-224, discussion 225-226

18 Lefever D, Perakis N, Roig M, Krejci I, Ardu S. The effect of toothbrushing on surface gloss of resin composites. Am J Dent 2012;25(1):54-58

19 Rizzi SC, Heath DJ, Coombes AG, Bock N, Textor M, Downes S. Biodegradable polymer/hydroxyapatite composites: surface analysis and initial attachment of human osteoblasts. J Biomed Mater Res 2001;55(4):475-486

20 Uçtaşli MB, Arisu HD, Omürlü H, Eligüzeloğlu E, Ozcan S, Ergun G. The effect of different finishing and polishing systems on the surface roughness of different composite restorative materials. J Contemp Dent Pract 2007;8(2):89-96

21 Aytac F, Karaarslan ES, Agaccioglu M, Tastan E, Buldur M, Kuyucu E. Effects of novel finishing and polishing systems on surface roughness and morphology of nanocomposites. J Esthet Restor Dent 2016;28(4):247-261

22 Kakaboura A, Fragouli M, Rahiotis C, Silikas N. Evaluation of surface characteristics of dental composites using profilometry, 
scanning electron, atomic force microscopy and gloss-meter. J Mater Sci Mater Med 2007;18(1):155-163

23 Yap AU, Yap SH, Teo CK, Ng JJ. Finishing/polishing of composite and compomer restoratives: effectiveness of one-step systems. Oper Dent 2004;29(3):275-279

24 Antonson SA, Yazici AR, Kilinc E, Antonson DE, Hardigan PC. Comparison of different finishing/polishing systems on surface roughness and gloss of resin composites. J Dent 2011;39(Suppl 1) :e9-e17

25 Başeren M. Surface roughness of nanofill and nanohybrid composite resin and ormocer-based tooth-colored restorative materials after several finishing and polishing procedures. J Biomater Appl 2004;19(2):121-134

26 Deljoo Z, Sadeghi M, Azar Mr, Bagheri R. The effect of different polishing methods and storage media on discoloration of resin composites. J Dent Biomater 2016;3(2):226-232

27 Venturini D, Cenci MS, Demarco FF, Camacho GB, Powers JM. Effect of polishing techniques and time on surface roughness, hardness and microleakage of resin composite restorations. Oper Dent 2006;31(1):11-17

28 Ritter AV. Posterior resin-based composite restorations: clinical recommendations for optimal success. J Esthet Restor Dent 2001;13(2):88-99

29 Rodrigues-Junior SA, Chemin P, Piaia PP, Ferracane JL. Surface roughness and gloss of actual composites as polished with different polishing systems. Oper Dent 2015;40(4):418-429

30 Lopes GC, Franke M, Maia HP. Effect of finishing time and techniques on marginal sealing ability of two composite restorative materials. J Prosthet Dent 2002;88(1):32-36

31 Jones CS, Billington RW, Pearson GJ. The in vivo perception of roughness of restorations. Br Dent J 2004;196(1):42-45, discussion 31
32 Shintani H, Satou J, Satou N, Hayashihara H, Inoue T. Effects of various finishing methods on staining and accumulation of Streptococcus mutans HS-6 on composite resins. Dent Mater 1985;1(6):225-227

33 Botta AC, Duarte S Jr, Paulin Filho PI, Gheno SM, Powers JM. Surface roughness of enamel and four resin composites. Am J Dent 2009;22(5):252-254

34 Mitra SB, Wu D, Holmes BN. An application of nanotechnology in advanced dental materials. J Am Dent Assoc 2003;134(10):1382-1390

$35 \mathrm{Lu} \mathrm{H}$, Lee YK, Oguri M, Powers JM. Properties of a dental resin composite with a spherical inorganic filler. Oper Dent 2006;31(6):734-740

36 Lohbauer U, Frankenberger R, Krämer N, Petschelt A. Strength and fatigue performance versus filler fraction of different types of direct dental restoratives. J Biomed Mater Res B Appl Biomater 2006;76(1):114-120

37 Beun S, Glorieux T, Devaux J, Vreven J, Leloup G. Characterization of nanofilled compared to universal and microfilled composites. Dent Mater 2007;23(1):51-59

38 Heintze SD, Forjanic M, Ohmiti K, Rousson V. Surface deterioration of dental materials after simulated toothbrushing in relation to brushing time and load. Dent Mater 2010;26(4):306-319

39 Paravina RD, Roeder L, Lu H, Vogel K, Powers JM. Effect of finishing and polishing procedures on surface roughness, gloss and color of resin-based composites. Am J Dent 2004;17(4):262-266

40 Kameyama A, Nakazawa T, Haruyama A, Haruyama C, Hosaka $\mathrm{M}$, Hirai Y. Influence of finishing/polishing procedures on the surface texture of two resin composites. Oper Dent 2008;2:56-60 